\title{
Testing methodologies for corrosion fatigue
}

\author{
E. Delmotte ${ }^{1}$; N. Micone ${ }^{1}$ and W. De Waele ${ }^{1}$ \\ ${ }^{1}$ Ghent University, Labo Soete, Belgium
}

\begin{abstract}
Offshore constructions are subjected to cyclic loading conditions. This situation is combined with the corrosive nature of the surrounding environment. It is of actual concern whether the combined effect is more damaging or not than the superposition of each effect independently. This literature review first introduces the reader to corrosion fatigue. Thereafter a critical comparison of some typical lab-scale fatigue corrosion test setups is given. Special emphasis is devoted to the instrumentation of the setup. This is followed by a design criteria summary which will be used to design a new corrosion fatigue test set-up for evaluating the fatigue properties of steel components in sea water environment.
\end{abstract}

Keywords: corrosion fatigue, test setup

\section{$1 \quad$ INTRODUCTION}

Worldwide fatigue is a significant problem for constructions under fluctuating loading conditions. A study of numerous industrial failures has shown that $77 \%$ of failures are due to fatigue. In Figure 1 the share of each failure mechanism, in the total of 242 investigated cases, is shown. It is clear that simple fatigue $(58 \%)$ is the biggest contributor, but low-cycle fatigue (8\%) and thermal, corrosion and low-cycle fatigue are not negligible (11\%) [1].

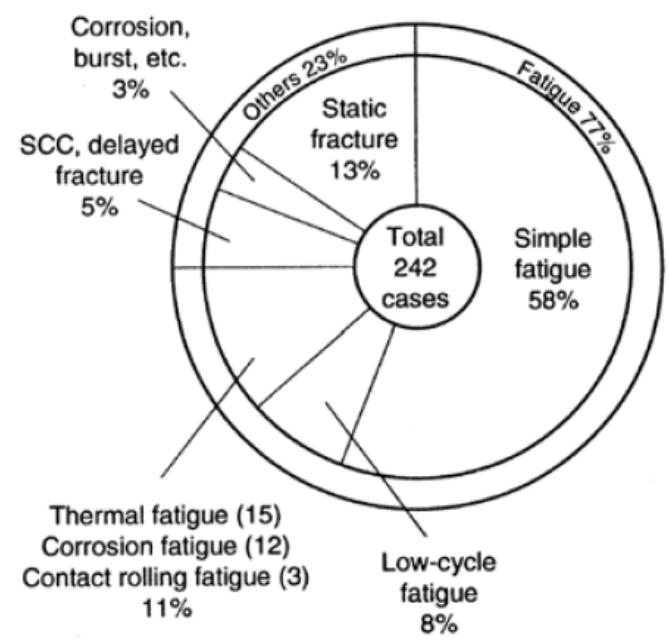

Figure 1: Type of failure in industrial failures [1]

Aging offshore infrastructure can experience up to 200 million wave-induced stress cycles of variable amplitude during their lifetime in the North Sea [2].Therefore, an accurate prediction of their lifetime is needed. According to the work of Stacey et al. [3] there are many constructions exceeding their original design life. The combined age of all operating platforms in the North Sea amounts to approximately 4000 years, with no major collapse due to structural failure alone.

Yet there are some examples of structural failures. A well-known example in the case of corrosion fatigue is the Alexander L. Kielland capsize [4]. This drilling platform capsized in the North Sea in 1980 resulting in 123 fatalities and 89 survivors. In the aftermath of the disaster, the investigation revealed that there were 
cracks, probably dating back from since the rig was built. The cracks developed over time, combined with corrosion, the remaining steel section at the region of failure initiation was less than 50 percent.

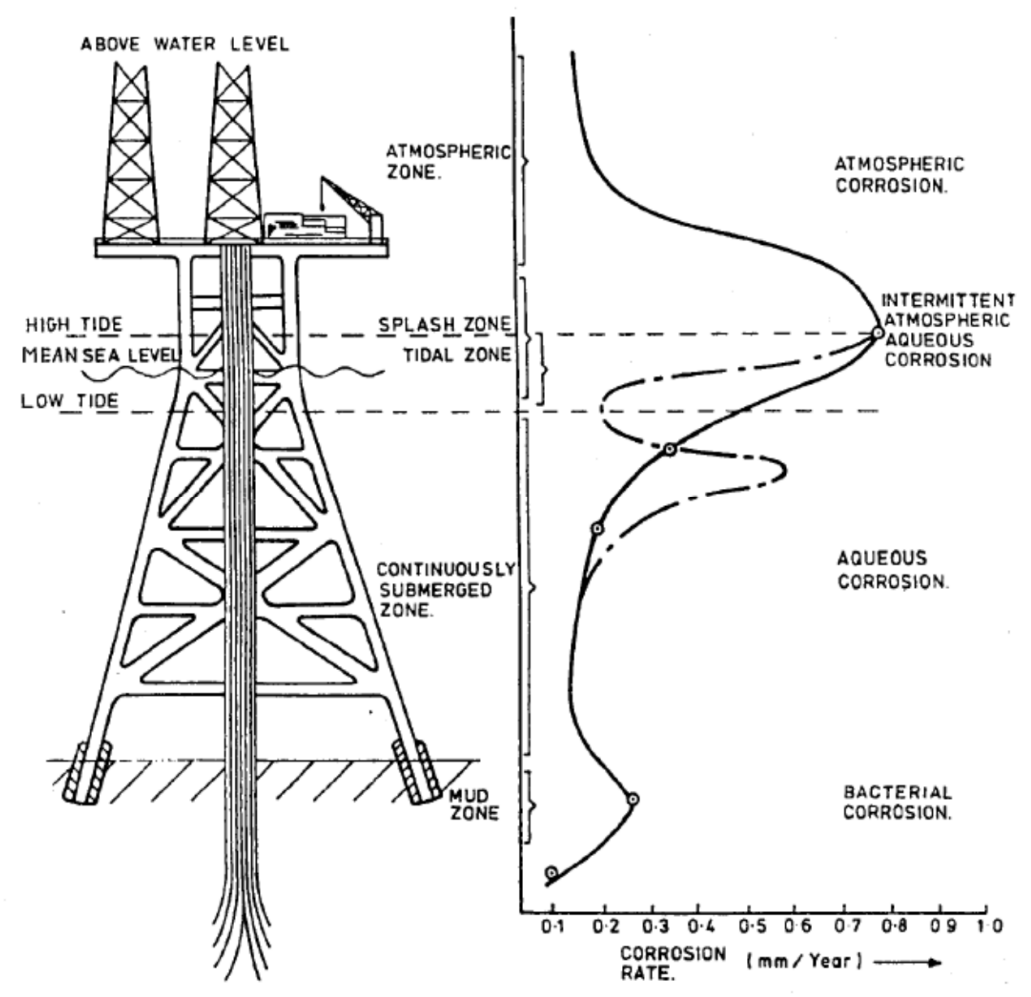

Figure 2: Diagram showing changes in environmental conditions which affect corrosion [5]

An offshore construction is subjected to corrosion at different areas [5]. As seen in Figure 2 there are four different zones each with a different corrosion rate.

These zones are:

- Atmospheric zone: where corrosion passes in air and salt spray.

- Splash and tidal zone: alternating periods of wet and dry, loaded by tidal and wave forces.

- Total immersion zone: water with decreasing oxygen level, subjected to underwater current and abrasion by sand and mud.

- Mud zone: sea water mixed with sand and mud and high level of anaerobic bacterial life.

Figure 2 clearly shows that an offshore construction is subjected to corrosion but also to cyclic loads, coming from tidal forces, wave forces and underwater currents. For this reason it is important to study the impact of corrosion in combination with fatigue loads to give an accurate estimation of life-expectancy.

This paper focusses on the requirements of a test setup to research corrosion fatigue in sea water environment. Furthermore corrosion fatigue test setups reported in literature are discussed. At the end a thorough description is given of the major components of such test setups.

\section{EXPERIMENTAL EVALUATION OF CORROSION FATIGUE}

As a result of this literature review a few typical and interesting designs of corrosion fatigue test setups have been selected. These setups can form a source of inspiration for the development of a sea water corrosion test rig. In the following a description of three test-setups can be found with additional critical discussion. Annex 1 provides a tabulated comparison of the three setups.

\subsection{Basic requirements}

Corrosion fatigue mechanisms are thoroughly described in [6]. Its effects on steel appear to be driven by two main mechanisms that either occur simultaneously or separately, namely: hydrogen-induced cracking 
and anodic dissolution at the crack tip. The test setup needs to allow the evaluation of these basic mechanisms. Corrosion fatigue is affected by a significant number of variables according to S. Pao [6]: mechanical variables, geometrical variables, metallurgical variables and environmental variables.

The environmental variables are:

- $\quad$ Concentration of damaging species in aqueous or other liquid environments

- Temperature

- $\mathrm{pH}$ value

- $\quad$ Electrochemical potential

- Viscosity of the environment

The test setup needs to be able to control these dominating parameters.

Temperature is one of the most important parameters for corrosion in sea water. It is observed that an increase in temperature leads to a significant increase in crack growth rate [6] (a rise from 5 to $20^{\circ} \mathrm{C}$ leads to doubling of crack growth rate [5]). This is caused by the increase of speed in the chemical reactions, leading to an increase of corrosion rate. By a test set-up, the temperature can be controlled by a cooling unit (see below).

Sour environments ( $\mathrm{pH}$ value lower than 7) speed up the corrosion process [7]. The $\mathrm{pH}$ of sea water is approximately 8.3 and globally constant [8]. The $\mathrm{pH}$-level can be monitored during testing and adjusted if necessary by adding chemical elements.

The concentration of microbiological life in the fluid has a direct relation to corrosion. Microbiological life enhances corrosion by either removing electrons from the material or forming additional corrosion products [9]. The effects of microbiological life can be avoided during testing by using pre-filtered sea water.

\subsection{Test setup for sour service corrosion fatigue testing of flow line welds}

\section{Description}

In the work of McMaster et al [7] a test setup is built to evaluate the corrosion fatigue behavior of production quality welds in X65 grade steel pipes. The tests take place in a sour brine environment consisting of water, $\mathrm{CO}_{2}$ and $\mathrm{H}_{2} \mathrm{~S}$. The fluid and vapor of this mixture are toxic and therefore dangerous in use. Therefore the setup consists of three chambers. Figure $3(\mathrm{a})$ is a photograph of the primary chamber. The chamber consists of a stainless steel body and is sealed with non-corrosive elastomeric ends. The precise material of this sealing is not mentioned. The chamber is not transparent, which makes it impossible to optically monitor corrosion and fatigue damage. The specimen size is 30 inch or approximately 75 centimeters.

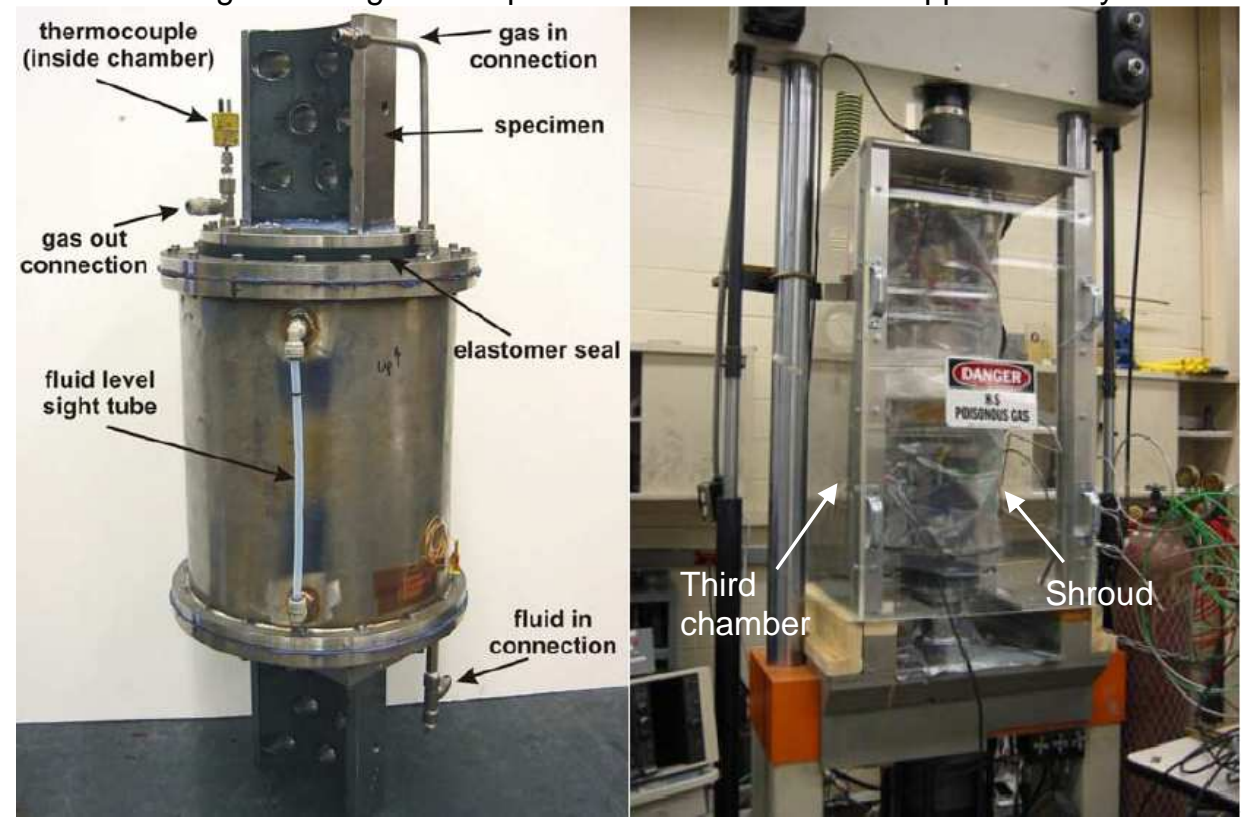

Figure 3: The environmental primary chamber (a) and complete sour brine environmental setup (b) [7] 
The second and third chamber (Figure 3 (b)) are present to ensure the safety of the operator. When there is a gas-leakage, the second chamber consisting of a shroud, will prevent the toxic gas from escaping. This chamber is sealed with O-rings. Through the shroud $\mathrm{N}_{2}$ gas is flowing to prevent $\mathrm{O}_{2}$ from intruding the primary chamber. It contains an $\mathrm{H}_{2} \mathrm{~S}$ detector connected to an alarm/shutdown panel. The third chamber, build around the second chamber, is a basic acrylic plate/aluminum frame construction, containing a ventilation system.

\section{Critical discussion}

This setup illustrates that it is possible to implement an environmental chamber on a test rig to perform medium-scale testing. Corrosion fatigue resistant elastic seals are used, though the precise material is not mentioned. The test setup is advanced for safety reasons. The safety precautions are necessary due to the dangerous fluid being used, bringing forth extra safety measures. For corrosion fatigue in offshore conditions, where sea water is being used, the fluid is harmless. This would lead to a simpler and cheaper design. A design with a triple containment chamber is not necessary.

The use of a stainless steel body for the primary chamber would imply additional problems as the impossibility of visual inspection.

The design only allows flowing of the gas products formed in the chamber and not recirculation of the corrosive fluid. Furthermore the primary chamber can only be used for testing of one specimen geometry, due to the clamping method. Analysis of different situations will depend on the availability of different seals and grips. The flexibility of the design is thus rather limited. There is no registration of crack growth, only the load on the specimen is registered. Therefore the only output of this setup are S-N curves.

\subsection{Corrosion fatigue of steel catenary risers in sweet production}

\section{Description}

Pargeter et al. [10] built a setup to test corrosion fatigue of welds used in catenary risers. The test device illustrated on Figure 4 consists of a large chamber mounted on a test bench. The test solution is circulated between a reservoir and the chamber. Both reservoir and chamber have a volume holding approximately 22 liters fluid. The solution is deaerated, contains $\mathrm{NaCl}, \mathrm{NaHCO}_{3}$ and is saturated with $\mathrm{CO}_{2}$. The test specimens are strip specimens of $800 \mathrm{~mm}$ long.

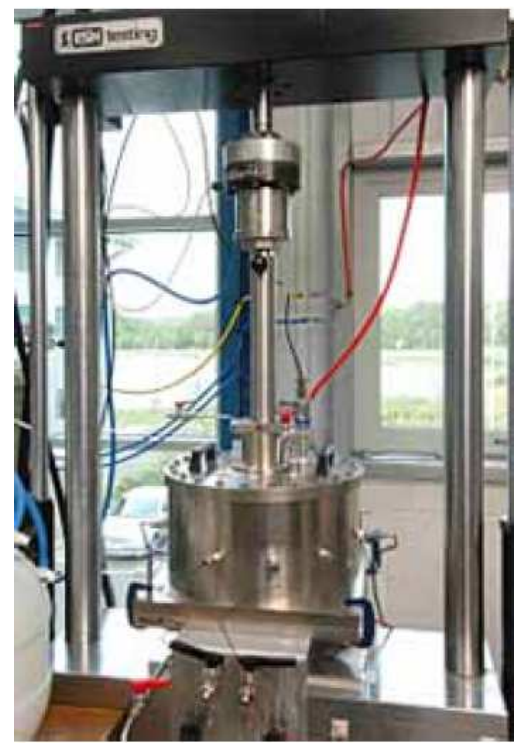

Figure 4: Corrosion fatigue crack growth rate equipment [10] 
An orbisphere monitors the oxygen content. A hot finger is incorporated in the circulation loop. A hot finger releases deposits of iron in a controllable rate, thereby controlling the concentration of iron in the solution. A scheme of the recirculation system can be seen in Figure 5.

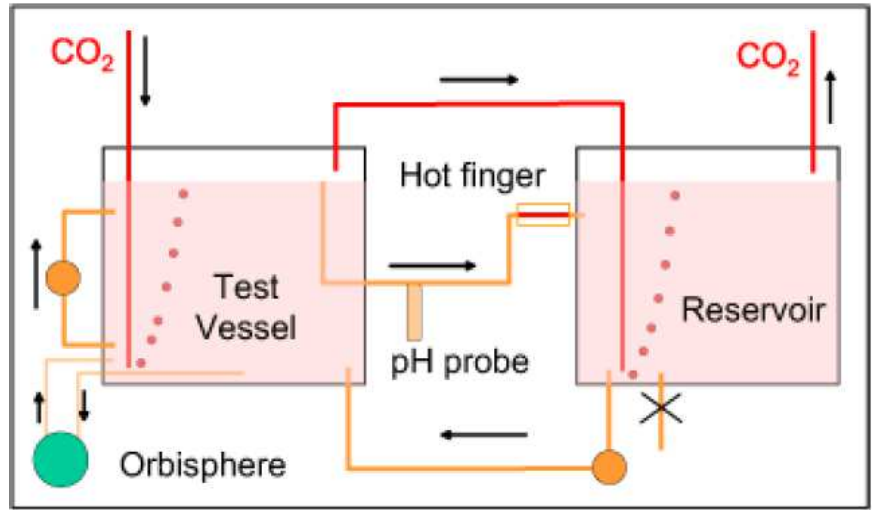

Figure 5: Recirculation system for test solution [10]

During testing the $\mathrm{pH}$, concentration of iron, oxygen and temperature are monitored. It is believed that the corrosion fatigue mechanism responsible is crack tip dissolution (see paragraph 2).

\section{Critical discussion}

The setup uses a circulating system which simulates a close to real environmental condition. A filtering and cooling system was not integrated in the setup. Therefore corrosion rate may be influenced by temperature and iron concentration. However these parameters are monitored through testing. The reason for lack of a cooling and filtering system may be the large volume of solution ( \pm 44 liter) making monitoring a more costefficient method.

Strain gauges were used to measure crack growth at the weld toe. This indicates that it is possible to submerse strain gauges in a corrosive fluid. There is no mentioning of any special precautions to protect the strain gauges however common sense leads to believe that a protective layer may have been used. The test setup is built for deep-sea oil applications. Although there are no dangerous vapors in this setup, the specimen has to be sealed to avoid intrusion of oxygen. The chamber, has a robust design that is not transparent which represents the same limitations as mentioned in 2.2.

\subsection{Fatigue crack initiation and growth in steel at the very high cycle regime with sea water corrosion}

\section{Description}

In the work of T. Palin-Luc et al [11] small-scale specimens are tested for crack initiation and crack growth. The VHCF (Very High Cycle Fatigue) tests are conducted on an ultrasonic fatigue testing machine. This type of testing rig works at resonance frequency of the specimens, in this case the frequency is $20 \mathrm{kHz}$. The geometry of this test rig influences the design of the environmental chamber (see Figure 6). For this type of test bench, sealing of the chamber is not required, simplifying the design. 


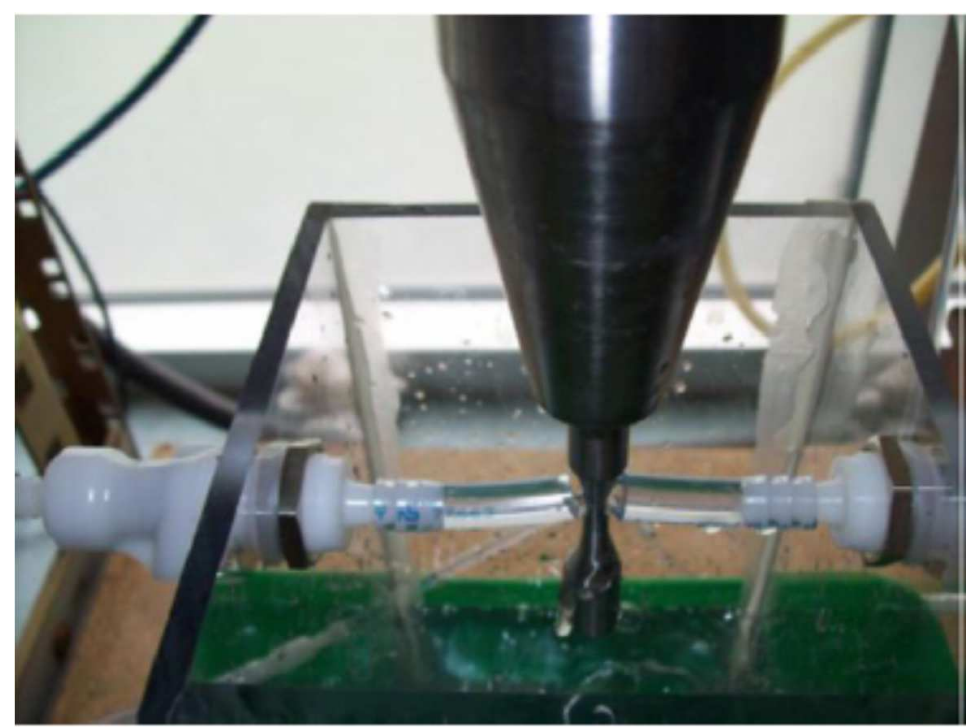

Figure 6: Corrosion fatigue cell [11]
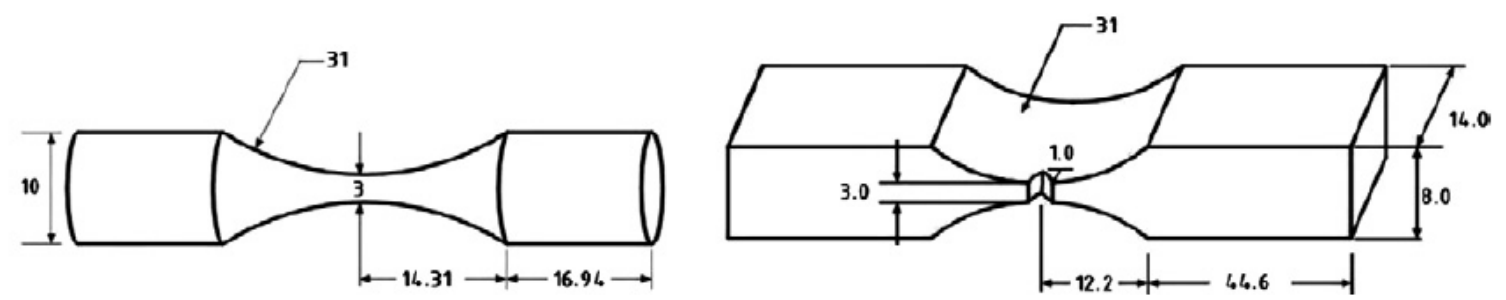

Figure 7: Specimen geometry for VHCF tests (left) and crack growth tests (right)

The specimens (shape and dimensions illustrated on Figure 7) are splashed upon by a peristaltic pump, without the specimen being immersed. The intention is to recreate the "splash zone", meaning the zone just above the surface of the sea where the water splashes up. The solution is sprayed upon the specimen on both sides with a flow rate of $100 \mathrm{ml}$ per minute through a $3 \mathrm{~mm}$ nozzle. The crack growth is measured with an optical binocular microscope.

The sea water used is $\mathrm{A} 3$ standard synthetic sea water with following chemical composition: $24.53 \% \mathrm{NaCl}$, $5.2 \% \mathrm{MgCl}, 4.09 \% \mathrm{Na}_{2} \mathrm{SO}_{4}, 1.16 \% \mathrm{Ca}_{2} \mathrm{Cl}$ and $0.201 \% \mathrm{NaHCO}_{3}$.

\section{Critical discussion}

Using a peristaltic pump to simulate a splash-zone is an interesting concept which definitely deserves some more investigation. The specimen is not immersed in sea water during the testing. T. Palin-Luc et al concludes: "ultrasonic fatigue test immersed in flowing sea water is the only experimental way to investigate very long life of steel under corrosion conditions." It is correct that ultrasonic fatigue testing is recommended for testing VHCF (very high cycle fatigue) in a short time window. However it is unlikely that the high frequency of testing compared to the slow corrosion process is representable for real-life situations. Furthermore, the test neglects influences of change in temperature and change in chemical composition with respect to the change in $\mathrm{pH}$. The setup is not controlled or heavily monitored making the results debatable.

A final remark which applies to all the test-setups discussed above: all testing was performed in artificial sea water neglecting any influence of microbiological organisms. It is understandable to decouple the influence of microbiological life to corrosion but could reduce the viability of the experiment in order to predict credible fatigue-life date usable in practice. 


\section{DESIGN CRITERIA FOR MAJOR TEST SET-UP COMPONENTS}

In order to come up with a design for an environmental chamber for corrosion fatigue testing some design criteria have to be set. In the following, the chamber, circuit design and materials will be discussed.

The intended test setup is a closed-loop circuit (Figure 8) that will consist of a chamber, tank, pump, filter unit and cooling unit. Adequate instrumentation will be required for monitoring of temperature, $\mathrm{pH}$ and salinity.

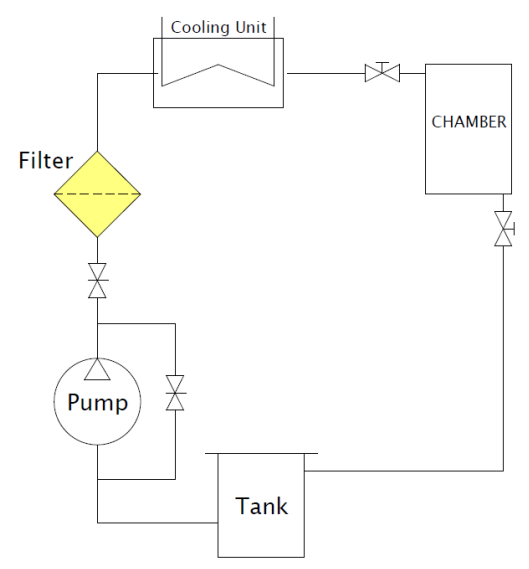

Figure 8: Scheme of the closed-loop circuit

\section{Chamber}

The chamber is the part of the test setup which will contain the corrosive fluid and the specimen. In this component the specimen will be fatigue loaded while the sea water flows across it. To this purpose, the chamber will need to meet some requirements.

Sealing of the chamber will be important. Leakage of the sea water fluid is not catastrophic but of course it is not desired. Furthermore the chamber will need to be adapted to different sizes of specimens. The specimens to be tested are so-called ESET specimens (eccentrically loaded single edge tension) with dimensions of $220 \mathrm{~mm}$ long by $60 \mathrm{~mm}$ wide and $15 \mathrm{~mm}$ thick [12], and round dog bone shaped bars with a length of $250 \mathrm{~mm}$ and a maximum diameter of $20 \mathrm{~mm}$. These dimensions lead to a minimum required space for the specimen with following dimensions: height of $250 \mathrm{~mm}$, width of $60 \mathrm{~mm}$ and a length of $20 \mathrm{~mm}$. Since the ESET specimens deflects outwards when they break, additional space is required. Sealing the chamber on the specimens is not possible due to the different geometries. Sealing will therefore need to be done on the test bench itself. Furthermore there will need to be some additional space for mounting of strain gauges, clip-on gages, etc. Yet the dimensions of the chamber will need to be limited. An increase of chamber volume leads to an increase of pumping power, cooling power and filtration capacity.

It is preferable to construct the chamber of a transparent material to have eyes on the specimen while testing. Therefore constructing the chamber out of acrylic is a viable solution.

\section{Pump}

The function of the pump is to circulate the sea water. It is critical for the pump to be corrosion resistant. Pumps used in aquariums of sea fish are designed to operate under these conditions and form a cheap solution. The head will be minimal 1.5 meters since this will be the estimated height of the chamber to the floor. Since there will be losses over the filter, cooling unit and bends, the head will need to be at least close to 4 meters. The flow rate has to be high enough to clean debris out of the chamber but it is not the intention to have water flowing across the specimen at high speed. Increasing flow velocity of the water will increase the corrosion rate [8]. To regulate the flow a bypass over the pump will be installed.

To simulate a splash zone, a peristaltic pump can be used as mentioned in 2.4. It is currently not the intention to simulate a splash zone, so opting for the aquarium pump is the logical decision. However the circuit will not need much adaptation to fit in a peristaltic pump in case splash zone-research is desired in the future. 


\section{Filter unit}

The size of beach sand and sea salt particles can be found in [13]. Beach sand particles have a size of 100 to 10,000 micrometer, sea salt 0.035 to 0.5 micrometer. The size of rust particles is unknown therefore a basic test using a coffee filter was performed. The filtration of the polluted water was sufficient, supporting the idea to use a filter with a particle size of 10 micrometers. Since most commonly used test-setups are not recirculating, filtration of seawater containing rust is not needed. In this setup however filtration is required and will need to be closely monitored during use of the setup, to avoid any unexpected anomalies. Furthermore to prevent clogging of the filter, pre-filtered sea water at 5 micron, will be used.

\section{Cooling unit}

The cooling unit will regulate the temperature of the water and keep it at a constant temperature during testing. The freezing point of sea water is $-2^{\circ} \mathrm{C}$, this is the temperature at which ice crystals start to form. This temperature will be the absolute lower limit of the cooling unit. The surface temperature of sea water ranges about $-2^{\circ} \mathrm{C}$ to $3^{\circ} \mathrm{C}$ worldwide [8]. Since most testing will happen at low temperatures there is no need to foresee a heating unit.

At great depths in the oceans the temperature barely fluctuates and amounts to about $10^{\circ} \mathrm{C}$. If deep-sea corrosion is investigated, this could be a reference temperature.

It is crucial that also the cooling unit is corrosion resistant. As mentioned above, keeping the dimensions of the chamber small will result in smaller amount of work for the cooling unit. Smaller volume results in faster cooling leading to a smaller start-up time for a test.

\section{Instrumentation}

As mentioned in point 2.1, corrosion fatigue is subjected to some environmental variables. It is important to monitor these variables in order to have a representative test result. The temperature in the chamber needs to be monitored. Normally the cooling unit will keep the temperature of the setup constant but it is safer to have a direct control inside the chamber as well. $\mathrm{A} \mathrm{pH}$ meter will control the acidity of the sea water. In nature the sea water has a stable $\mathrm{pH}$-value of 8.3 [6]. It is logical to keep the $\mathrm{pH}$ level constant in order to simulate real-life conditions. Furthermore a control of salinity will be required. The salinity might increase by evaporation and escape of water vapor. There is a direct link between conductivity and salinity, measuring the conductivity of the water is the working principle of the most commercial salinity meters.

The concentration of microbiological life will not need to be monitored when working with artificial sea water or pre-filtered sea water. For this and other reasons (such as accessibility, chemical stability, no polluting particles, etc.) pre-filtered sea water is the most logical choice.

There are many different measurement methods used in fatigue testing such as DCPD (direct current potential drop), infrared thermography, strain gauges, clip-on gages... For DCPD there will be interference with the measurement probes for salinity and $\mathrm{pH}$ as these are based on the conductivity of the water. Therefore DCPD cannot be used in a submerged environment. Sea water is also not transparent in the infrared spectrum making infrared thermography inapplicable in the test-setup. Strain gauges however can be submerged and therefore used to monitor crack growth.

\section{CONCLUSION}

As stated in the introduction there is a need for research of corrosion fatigue in sea water. Thereto the development of an environmental chamber in a traditional fatigue testing rig is a sound solution. The design of such a test setup is feasible as illustrated by the discussed test setups in this paper. Furthermore monitoring of loads can be done by the load cell of the traditional test rig, crack growth can be monitored by strain gauges. Testing with pre-filtered sea water will give a more real-life result than testing with artificial sea water. By using a circulating circuit the use of sea water can be limited. The test setup will consist of a chamber where the actual testing takes place, a pump, filter unit, cooling unit and instrumentation to monitor the environmental variables. This test setup has to be capable of performing corrosion fatigue tests in a sea water environment with a constant temperature, $\mathrm{pH}$ and salinity. A fully functioning setup will be capable of producing test results leading to an increased knowledge of corrosion fatigue of offshore structures. 
[1] ASM International, ASM Handbook Vol. 19 Fatigue and Fracture vol. 19. United States of America, 1996.

[2] J. C. P. Kam, "Recent Development in the Fast Corrosion Fatigue Analysis of Offshore Structures Subject to Random Wave Loading," International Journal of Fatigue, vol. 12, pp. 458-468, Nov 1990.

[3] A. Stacey and J. V. Sharp, "Safety factor requirements for the offshore industry," Engineering Failure Analysis, vol. 14, pp. 442-458, Apr 2007.

[4] European Union Offshore Authorities Group. (2014, 8/11/2014). Landmark Incidents [Web Page]. Available: http://euoag.jrc.ec.europa.eu/node/41

[5] P. G. Millar, "Corrosion Fatigue Crack Propagation Behaviour of a High Strength Low Alloy Steel in a Synthetic Sea Water Environment," PhD PhD, Cranfield Institute of Technology, 1986.

[6] P. S. Pao, "Mechanisms of Corrosion Fatigue," in ASM Handbook Vol. 19 Fatigue and Fracture, P. S. Pao, Ed., ed.

[7] F. McMaster, H. Thompson, M. Zhang, D. Walters, J. Bowman, and Asme, Sour service corrosion fatigue testing of flowline welds. New York: Amer Soc Mechanical Engineers, 2007.

[8] J. C. Rowlands, "Sea Water," in Corrosion. vol. 1, 3 ed Oxford Auckland Boston Johannesburg Melbour New Delhi: Butterworth-Heinemann, 2000, pp. 2.60-2.71.

[9] D. E. Hughes, "The Microbiology of Corrosion," in ASM Handbook Vol. 19 Fatigue and Fracture, ed, 1996.

[10] R. Pargeter, D. Baxter, B. Holmes, and Asme, Corrosion Fatigue of Steel Catenary Risers in Sweet Production, 2008.

[11] T. Palin-Luc, R. Perez-Mora, C. Bathias, G. Dominguez, P. C. Paris, and J. L. Arana, "Fatigue crack initiation and growth on a steel in the very high cycle regime with sea water corrosion," Engineering Fracture Mechanics, vol. 77, pp. 1953-1962, Jul 2010.

[12] ASTM International, "ASTM E647 Standard Test Method for Measurement of Fatigue Crack Growth Rates," in THE ECCENTRICALLY-LOADED SINGLE EDGE CRACK TENSION SPECIMEN, ed. United States, 2014.

[13] The Engineering Toolbox. (n.d., 13/11). Sizes of airborne particle as dust, pollen bacteria, virus and many more. Available: http://www.engineeringtoolbox.com/particle-sizes-d 934.html 


\section{ANNEX}

Annex 1: comparison test-setups

\begin{tabular}{|c|c|c|c|}
\hline & Paragraph 2.2 & Paragraph 2.3 & Paragraph 2.4 \\
\hline \multicolumn{4}{|l|}{ Chamber } \\
\hline Shape & circular & circular & box \\
\hline Material & stainless steel & corrosion resistant steel & acryl \\
\hline Relative volume & small & large & large \\
\hline \multicolumn{4}{|l|}{ Fluid } \\
\hline Circulating/stationary & stationary & circulating & circulating \\
\hline Immersion specimen & yes & yes & no \\
\hline Environment simulation & deep-sea sour conditions & deep-sea sweet conditions & sea-surface conditions \\
\hline Components & $\mathrm{H}_{2} \mathrm{O}, \mathrm{CO}_{2}, \mathrm{H}_{2} \mathrm{~S}, \mathrm{~N}_{2}$ & $\mathrm{H}_{2} \mathrm{O}, \mathrm{NaCl}, \mathrm{NaHCO}_{3}, \mathrm{CO}_{2}$ & A3 standard synthetic sea water \\
\hline Salinity & $0 \%$ & $3.5 \%$ & $3.5 \%$ \\
\hline \multicolumn{4}{|l|}{ Circuit } \\
\hline Control parameters & temperature, $\mathrm{pH}$ & temperature, oxygen, $\mathrm{pH}$, ironconc. & flow \\
\hline \multicolumn{4}{|l|}{ Testing } \\
\hline Specimen size & medium-scale & small-scale & small-scale \\
\hline Fatigue test setup & servo-hydraulic test frame & servo-hydraulic test frame & ultrasonic fatigue testing machine \\
\hline Data obtained & endurance & crack growth rate/ endurance & crack growth rate/ endurance \\
\hline
\end{tabular}

